\title{
Social transmission of courtship behavior and mating preferences in brown-headed cowbirds, Molothrus ater
}

\author{
TODD M. FREEBERG \\ University of Tennessee, Knoxville, Tennessee
}

\begin{abstract}
Studies of the social learning of courtship behaviors and mating preferences of brown-headed cowbirds (Molothrus ater) are reviewed. Earlier work has suggested that cowbirds from behaviorally distinct populations mate preferentially with others from the same population. Studies are described which indicate that patterns of courtship behavior that differ by population can be socially transmitted across generations are described. Social background affects male songs, female preferences for males as mates, and courtship interactions between females and males. Thus, social traditions influence mating decisions and may, ultimately, impact reproductive success in this species. Recent work on possible social mechanisms involved in the ontogeny of courtship behavior is described. The implications of these findings are discussed, and future research directions are suggested.
\end{abstract}

In brown-headed cowbirds, Molothrus ater, as in most songbird species (the oscines), males' songs are fundamental to successful reproduction (Catchpole \& Slater, 1995; Kroodsma \& Miller, 1996; Rothstein, Yokel, \& Fleischer, 1986; West, King, \& Eastzer, 1981), and males learn the particular songs that they sing (Freeberg, King, \& West, 2001; Kroodsma \& Miller, 1996; O'Loghlen \& Rothstein, 1993, 2002; West, King, \& Harrocks, 1983). Furthermore, females learn their preferences for males as mates (Freeberg, Duncan, Kast, \& Enstrom, 1999) and, possibly, for males' songs (King \& West, 1987). Finally, the social group within which male and female cowbirds develop provides a social context for such learning to occur. The aim of this article is threefold: (1) to review studies that indicate social transmission of cowbird courtship behaviors and mating preferences, (2) to describe recent work on some possible mechanisms of social learning involved in this social transmission, and (3) to suggest future avenues of research in this and other species to describe both flexible learning strategies in individuals and adaptive learning patterns in populations.

I thank Meredith J. West and Andrew P. King, as well as the Department of Biology at Indiana University, for assistance with these studies and for providing a wonderful social-learning environment in which to study social learning. Thanks also to the many undergraduates at Indiana University for their assistance with data collection during the various studies described here. Thanks to Gordon Burghardt, Daniela Corbetta, and Jeff Galef for providing valuable feedback on earlier versions of this manuscript and to Fred McDowell, as always, for philosophical guidance. Correspondence concerning this article should be addressed to T. M. Freeberg, Department of Psychology, Austin Peay Building 303A, University of Tennessee, Knoxville, TN 37996 (e-mail: tfreeber@utk.edu).

\section{SOCIAL TRANSMISSION OF COURTSHIP PATTERNS}

Traditional views of courtship behaviors and mating preferences in animals have held that these behaviors are largely innate (e.g., Fisher, 1958; Lorenz, 1932/1970; Mayr, 1974). However, recent studies in a variety of taxa have indicated that learning can influence both courtship and mating. For example, the pairing of various stimuli with presentation of a mate leads to the classical conditioning of courtship behaviors in blue gouramis (Trichogaster trichopterus; Hollis, Pharr, Dumas, Britton, \& Field, 1997), threespine stickleback (Gasterosteus aculeatus; Jenkins \& Rowland, 1996, 1997), and Japanese quail (Coturnixjaponica; Domjan, Blesbois, \& Williams, 1998; Gutierrez \& Domjan, 1997; Köksal \& Domjan, 1998). Furthermore, imprinting studies (Hess, 1973) have indicated that young birds cross-fostered with morphologically or behaviorally distinct adults can later exhibit sexual preferences for birds with the characteristics of their foster parents (e.g., mallards [Anas platyrhynchos], Kruijt, Bossemma, \& Lammers, 1982; collared doves [Streptopelia decaocto], ten Cate, Hilbers, \& Hall, 1992; and zebra finches [Taeniopygia guttata], Clayton, 1990, Kruijt \& Meeuwissen, 1991, ten Cate, 1984, and Vos, 1994). Experience in observing courtship interactions between females and males can influence the mating preferences of guppies, Poecilia reticulata (Dugatkin, 1992; Dugatkin \& Godin, 1992; but see Brooks, 1996) and Japanese quail (Galef \& White, 1998; White, 2004; White $\&$ Galef, 1999, 2000).

Brown-headed cowbirds are obligate brood parasites. During the breeding season, female cowbirds lay their eggs in nests of other species, with the result that young 
cowbirds are always raised by noncowbird host species (Ortega, 1998). In late summer, after reaching independence from their host parents, young cowbirds join flocks formed primarily of other young cowbirds (Friedmann, 1929; Woodward, 1983). Over the winter, the young cowbird is typically found in very large flocks consisting of cowbirds and other (often blackbird) species.

Earlier work with cowbirds has indicated that birds from behaviorally distinct populations court and mate assortatively during the breeding season (Eastzer, King, $\&$ West, 1985). This type of assortative mating (positive assortative mating) can increase the homozygosity of genes affecting the particular courtship behaviors on which mating preferences are based and can, thereby, impact evolutionary change in populations (Hartl \& Clark, 1989). I was interested in determining whether the social experiences of young cowbirds during the overwintering months can influence behaviors that result in assortative mating. Social learning of these behaviors may provide a means by which learning processes and behavioral interactions in these populations can influence their evolution (Lewontin, 1983).

\section{First "Cultural” Generation Study}

The basic method for testing whether a bird's social background can influence its courtship behaviors and mating preferences was a variation of a design for generating laboratory microcultures (see Galef \& Allen, 1995), in which behaviorally distinct populations of adult cowbirds are used as models for groups of young and relatively naive cowbirds. I used groups of adult cowbirds from a southern Black Hills, South Dakota population (M. a. artemisiae) and from a south-central Indiana population (M. a. ater) as the original adult social models. These populations are behaviorally different from one another in at least two important respects. First, the songs of males are structurally distinct, with the numbers of notes in the note clusters making up the songs showing large differences by population (Freeberg et al., 2001; described further below). Second, females from these two populations show preferences for the songs of the males in their own populations, relative to those of the males in other populations, as assayed by the numbers of copulation solicitation displays given to playbacks of the males' songs (West, King, \& Freeberg, 1998).

Phase I: Social background housing. During this study, I housed young female and male cowbirds over the winter with adult social models from either Indiana or South Dakota and then tested the courtship patterns and mating preferences of those young birds during the breeding season (Freeberg, 1996). During the first cultural generation study, I observed and tested this cohort of young females and males over their first two breeding seasons. I captured the subjects in the southern Black Hills in South Dakota in early August of 1993. At the time of capture, the young birds were in large flocks of other young cowbirds and were judged to be 50-100 days of age. I housed roughly half of the young birds in two large outdoor/indoor aviaries with adults from the same South Dakota population (young cowbirds in this group will be labeled SDC1 birds for South Dakota culture, first generation). I housed the remainder in two large outdoor/indoor aviaries with adults from the Indiana population (young cowbirds in this group will be labeled INC1 birds for Indiana culture, first generation). Birds were housed together until early May of the following year, at which time the courtship behaviors of the SDC1 and INC1 birds were examined (Figure 1).

Phase II: Pairing assessment. I tested the courtship behaviors and mating patterns of the SDC1 and INC 1 birds during the cowbirds' breeding season (mid-May to early July) in a large outdoor/indoor pairing assessment aviary. Groups of SDC1 and INC1 males from one set of overwintering aviaries were tested with groups of SDC1 and INC1 females from the replicate aviaries, to control for effects of individual familiarity between females and males. The major dependent measure was consistent courtship behavior between individual females and males (based primarily upon persistent vocalizing from a male to a female in close proximity, often resulting in copulations; see also Eastzer et al., 1985; Freeberg, King, \& West, 1995).

Following their first breeding season, I housed the young SDC1 and INC1 birds with their respective South Dakota and Indiana social models for another overwintering period (August 1994 to May 1995). From May through July 1995, the second breeding season for the young birds, the courtship behaviors of the SDC and INC birds were again tested.

Findings. During their first two breeding seasons, SDC1 females paired more often with SDC1 males, and INC1 females paired more often with INC1 males. In their first breeding season, I documented 21 unique courtship pairings between females and males, of which $15(71 \%)$ were between females and males of the same social background (INC1 birds with INC1 and SDC1 with SDC1 birds). In their second breeding season, the positive-assortative mating patterns of SDC1 and INC1 females were even stronger; of 32 unique courtship pairings between females and males, $26(81 \%)$ were between females and males of the same social background. Taken together, then, these data indicate that patterns of assortative mating seen in brown-headed cowbirds (see, e.g., Eastzer et al., 1985) can be strongly influenced by the birds' social background during the overwintering months.

\section{Second "Cultural" Generation Study}

Results from the first cultural generation study indicated that the courtship behaviors and mating patterns of female cowbirds could be socially learned. The purpose of the second cultural generation study was to determine whether those SDC1 and INC1 females and males could, in turn, pass their behavioral patterns on to another generation of young birds, in the absence of the original adult South Dakota and Indiana social models (Freeberg, 1998).

Phase I: Social background housing. I captured the cohort of young cowbirds for the second cultural gener- 


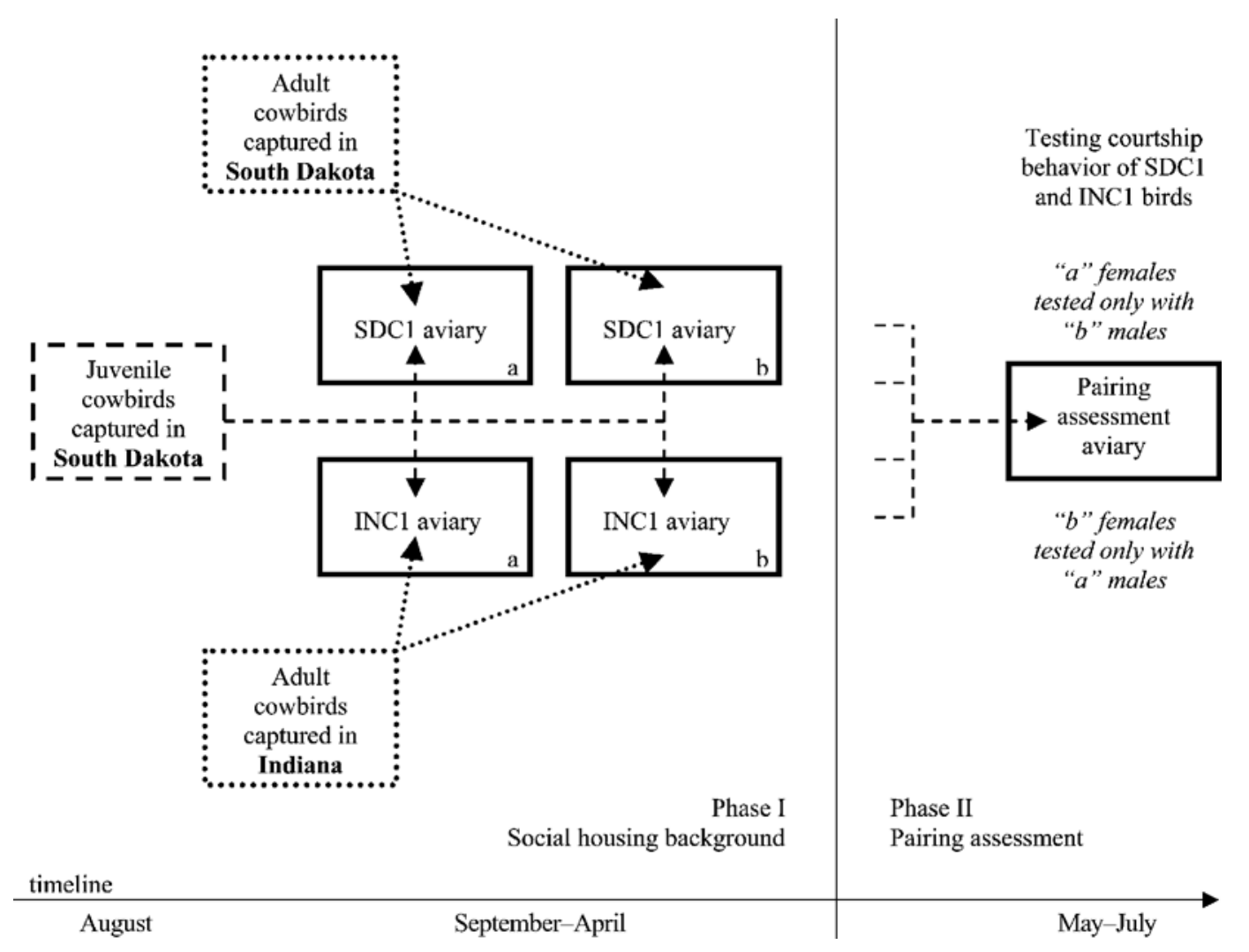

Figure 1. Design for testing social-learning and mating patterns in birds of the first cultural generation study. Adult models were from either South Dakota or Indiana. The design for testing the social transmission of courtship behaviors and mating patterns in birds of the second cultural generation study was identical, except for the key difference that the second cohort of young from South Dakota was exposed either to the adult South Dakota culture, first generation (SDC1) birds that had been exposed to South Dakota birds or to the adult Indiana culture, first generation (INC1) birds that had been exposed to Indiana birds.

ation study in the southern Black Hills in South Dakota in early August of 1995. I housed roughly half of the young birds in two large outdoor/indoor aviaries with the SDC1 adults (young cowbirds in this group will be labeled $S D C 2$ birds for South Dakota culture, second generation). I housed the remainder of the young birds in two large outdoor/indoor aviaries with INC1 adults (young cowbirds in this group will be labeled INC2 birds for Indiana culture, first generation). Note that during the second cultural generation study, both the models and the naive birds were genetically South Dakota birds, all captured originally from the same southwestern South Dakota population. The only difference between the SDC2 and the INC2 birds was in the social backgrounds of their SDC1 and INC1 adult social models. I housed the birds together until early May of the following year, at which time I tested the courtship behaviors of the SDC2 and INC2 birds (and conducted mate choice tests of SDC1 and INC1 females).

Phase II: Pairing assessment. I tested the courtship behaviors and pairing patterns of SDC2 and INC2 birds, using the same methodology as that used to assess pairing patterns in birds of the first cultural generation study.
Also, as with the earlier study, to control for effects of individual familiarity between females and males, I tested SDC2 and INC2 females with SDC2 and INC2 males from the replicate aviaries with which they had had no individual contact.

Findings. As was the case with the SDC1 and INC1 females, the SDC2 and INC2 females paired with males from their own social background. I documented 31 unique courtship pairings between the females and the males, of which $22(71 \%)$ were between females and males of the same social background. These data indicate that the patterns of courtship behavior that facilitate assortative mating at the population level can be socially transmitted across generations in this species.

\section{Social Background and Female Mate Choice}

The studies described above indicated that an individual's social background can influence the courtship behaviors and mating patterns it develops. I collected these data in a pairing assessment aviary, using a multiplechoice design, in which each SDC and INC female had several SDC and INC males as potential mates from which 
to choose. Because the birds were tested in groups, I was not able to rule out effects of male-male competition or, possibly, female-female competition for mates or of social modeling by familiar animals during the breeding season on assortative mating patterns. Consequently, my colleagues and I tested individual SDC1 and INC1 females, using a sequential mate choice design to control for intrasexual interactions (Freeberg et al., 1999).

Parallel with the 1996 pairing assessment aviary testing with the SDC2 and INC2 females and males, we tested SDC1 and INC1 females for their mating preferences for SDC1 and INC1 males in small outdoor cages (each roughly $2 \times 3 \times 2 \mathrm{~m}$ ). During the cowbirds' breeding season, we housed each female with a male of one social background for 3 successive days and then housed the female with a male of the other social background for 3 successive days. We counterbalanced order of SDC 1 and INC1 male presentations across females.

We tested the mate choice of 9 SDC1 and 9 INC1 females, with each female being tested twice over the course of the breeding season. Our dependent measures were similar to those used to establish courtship pairings in large aviaries - that is, males consistently singing to females from close proximity, female copulation solicitation displays, and copulations.

Findings. As was suggested by the multiple-choice testing of the first and second cultural generation studies, the results obtained in this study indicated that female mate preferences could be influenced by social background. In the first round of testing for each female, 8 of the $9(89 \%)$ INC1 females and 7 of the $9(78 \%)$ SDC1 females exhibited mating preferences for males of their own social background. Mate choice patterns in the second round of testing were more equivocal, but in summing the scores across females over the two rounds of testing, we found that 10 females exhibited mate choice for males of their own social background, whereas only 1 female exhibited mate choice for males of the other social background (with 7 females exhibiting mate choice for males of both social backgrounds). Thus, these data indicate that the social background of a female cowbird can directly influence its mating preferences.

\section{Social Transmission of Male Song}

Given that songs of a male directed to a female are fundamental to the courtship system in brown-headed cowbirds, I wanted to determine whether differences in the songs of South Dakota and Indiana males could be transmitted across the SDC1/SDC2 and the INC1/INC2 generations, respectively. Consequently, my colleagues and I analyzed recordings of the mature breeding-season songs of the males in the studies described above, to assess whether population and/or social background differences existed and, if so, whether these differences might be predictive of the courtship interactions of males during the breeding season (Freeberg et al., 2001).

Early in each of the breeding seasons described above, in the week or two prior to the testing of the birds for courtship patterns and mating preferences, we recorded the songs of each male. The final data set comprised 90 males and over 19,000 songs across the 3 years of the study.

Male brown-headed cowbird song typically consists of two to three clusters of individual low-frequency notes, followed by a high-frequency whistle. As a first description of differences in the songs of South Dakota and Indiana birds, we counted the number of notes in each of the first three note clusters of the males' songs. We then averaged the number of notes in the note clusters of songs for each male.

Findings. We found that Indiana males had significantly more notes in their first note cluster (mean of 5.89 notes $\pm 0.16 S E$ ) than did South Dakota males $(4.31 \pm$ 0.18 notes) and had significantly fewer notes in their third note clusters $(0.43 \pm 0.20$ notes $)$ than did South Dakota males ( $3.43 \pm 0.20$ notes). In fact, Indiana males rarely had a third note cluster in their songs.

These differences in the average number of notes in the first and the third note clusters were transmitted across generations. In other words, the note numbers of SDC1 and SDC2 males were very similar to those of South Dakota males, and the note numbers of INC1 and INC2 males were very similar to those of Indiana males. Differences between SDC1 and INC1 males and between SDC2 and INC2 males were as great as the differences between South Dakota and Indiana males.

Importantly, the relative numbers of notes in the first two note clusters of the males' songs were highly predictive of their courtship interactions and effectiveness. The more "South-Dakota-like" a male's songs were (in general, more notes in the second note cluster than in the first note cluster), the more likely that male was to be successful at courting and pairing with females from the South Dakota social background (i.e., SDC1 females for SDC1 males and SDC2 females for SDC2 males). Conversely, the more "Indiana-like" a male's songs were (in general, more notes in the first note cluster than in the second note cluster), the more likely that male was to be successful at courting and pairing with females from the Indiana social background (i.e., INC1 and INC2 females).

To summarize the studies described thus far, there is experimental evidence that the social background of a bird can influence its courtship behaviors and mating preferences. Furthermore, populationally distinct behaviors and mating patterns can be transmitted across at least two generations of cowbirds. The mechanisms of this social learning and transmission are unknown. However, recent work has begun to address this question and will be discussed briefly in the next section.

\section{SOCIAL MECHANISMS OF LEARNING}

As part of the research described above, I collected data on how the SDC1, SDC2, INC1, and INC2 birds spatially associated in the aviaries in which they were housed over the winter. To determine the structures of spatial association in the aviaries, I scored nearest neighbor data 
points for each individual many times during the weeks prior to testing courtship patterns and mating preferences during the breeding season. I found that social structures in these aviaries were built, first, around sex and, second, around age (Freeberg, 1999). Young SDC males were found most often near other young SDC males, second most often near the adult South Dakota male social models, and third most often near the females. Similarly, young INC males were found most often near other young INC males, second most often near the adult Indiana male social models, and third most often near the females. Finally, young SDC and INC females were found most often near other young SDC and INC females, in their respective aviaries, second most often near the adult South Dakota and Indiana female social models (respectively), and third most often near the males. These social structures were maintained in the second cultural generation study with the SDC1/SDC2 groups, as well as with the INC1/INC2 groups (Freeberg, 1999).

The study described above suggested that the context for social learning for young cowbirds may occur in the close-proximity spatial associations males and females have with other cowbirds. Young females and males seemed to associate predominantly with others of their same age and sex class and second most often with adults of the same sex. These results argue for the need to look much more closely at the associations between young males and other males and between young females and other females. In recent work by Andrew King, V. Anne Smith, Meredith West, and David White, this question has been pursued, particularly with regard to the proximal networks (Smith, King, \& West, 2002) of young males and how interactions in these structures may influence the subsequent courtship effectiveness of these males.

In a study conducted on a much larger scale than the Freeberg (1999) study described above, Smith et al. (2002) observed in detail and longitudinally the spatial associations among 74 young and adult female and male Indiana cowbirds in a 2,500- $\mathrm{m}^{3}$ outdoor/indoor aviary complex. The aviary complex was so large and structurally complicated that individuals could freely choose to associate or not associate with other individuals. As with Freeberg's (1999) study, the birds associated most frequently with birds of the same sex and age class, second most frequently with birds of the same sex but a different age class, and least often with birds of the opposite sex. In addition, young males that had associated frequently over the winter with adult males paired with females more quickly during the breeding season than did young males that had associated rarely over the winter with adult males. Furthermore, young males that sang more throughout the overwintering period associated less with females over that period. This finding is important in that rates of vocalizing over winter can correlate with rates of song development (King, Freeberg, \& West, 1996) and female interactions with young males can affect males' vocal development(West \& King, 1988).
Smith et al.'s (2002) study raised the exciting possibility that young cowbirds actively engage their social environments in the development of their communicative and courtship abilities. Young birds may seek out interactions with adult birds, and frequency of interactions with adults may influence later abilities of young birds to obtain mates during the breeding season. Thus, the presence or absence of adults (and particularly adult males for young males) would be an important variable to manipulate experimentally to determine the effects of this factor on the development of young birds. White, King, Cole, and West (2002) did just this in a study of very young (but independent) males' social and vocal behavior in late summer. The experiments in this study were conducted during the time at which young birds begin flocking in the wild.

White, King, et al. (2002) monitored the spatial associations and vocal productions of two groups of young males housed in aviaries with young females. One group of young males also had adult males present ( $J A$ for $J u$ venile and Adult birds) and the other group did not ( $J$ for Juvenile only birds). The young males in the JA condition associated much more frequently with other young males than did the young males in the $J$ condition and did so within 4 days of the birds' placement in the experimental aviaries. In other words, the associations of young males are affected by the presence of adult males in the social environment and can be established extremely rapidly. The J males had higher vocal output during these experiments than did the JA males. Finally, the JA males began to show association and vocal patterns like those of the J males, and vice versa, shortly after the adults were moved from the JA aviary into the $\mathrm{J}$ aviary. Apparently, the social associations and affiliations of young male cowbirds are tightly linked not so much to the presence of other young males or young females as to the presence of adult males in the social environment.

In another recent study in which the linkage between interactions with adult males and social and vocal development in young male cowbirds was tested, the functional implications of interactions with adult males were explored in detail. White, King, and West (2002a) studied a set of JA young males in an aviary with both adult and juvenile females and also with adult males and a set of $\mathbf{J}$ young males in an aviary with adult and juvenile females but with no adult males. The birds were followed from late summer until the following breeding season. The JA males exhibited more male-male aggression and nearest neighbor associations with one another than did the J males. The JA males also directed songs toward individual females more consistently. Whereas the J males and the JA males directed an equal number of songs to females, the J males exhibited a strategy atypical of cowbirds, by singing to many different females.

Whereas both the $\mathrm{J}$ and the JA male groups were successful at obtaining pairings and copulations with females, the courtship behaviors that correspond with pair- 
ing and mating were different in the two groups. The JA males spent considerably more time guarding their consort females than did the J males. As assayed by playback studies to females, the $\mathrm{J}$ males developed songs that were more effective at eliciting copulatory solicitation displays from females (i.e., more potent songs) than did the JA males. This finding is consistent with earlier studies indicating that young males tend to develop more potent songs in the absence of dominant older males (Freeberg et al., 1995; West \& King, 1980).

In summary, the studies described above indicate that young male cowbirds, after reaching independence, inhabit an extremely rich and structured social environment, actively engage in social interactions in that environment, and are profoundly affected by those interactions. The presence of adult males generates a social structure different from that generated in their absence, and these different social structures have effects on male development that are expressed in breeding season activity with females. Females also appear to be affected by the presence of adult males over the winter. Social structures of adult and young females were found to differ depending on whether vocalizing adult males were present in overwintering aviaries (Gros-Louis, White, King, \& West, 2003). Furthermore, females from aviaries with adult males had higher reproductive output the following breeding season than did females from aviaries lacking adult males (West, White, \& King, 2002). Thus, even though young females may not associate frequently or closely with adult males over the winter months, their behavioral development appears to be sensitive to the presence of adult males.

Finally, recent studies have indicated that interactions between young and adult males have breeding season effects that run both ways. Adult male courtship effectiveness is also impacted by interactions with young males. Adult males housed over winter in aviaries with young males were more successful at obtaining copulations with females during the following breeding season than were adult males housed over winter in aviaries without young males (White, King, \& West, 2002b). The picture that emerges from this work is that the social structures that exist in overwintering flocks of cowbirds have powerful shaping effects on male and female courtship behaviors and that these social structures themselves are highly dynamic organizational units.

\section{CONCLUSIONS AND SUGGESTIONS FOR FUTURE RESEARCH}

The results of the studies with brown-headed cowbirds described here indicate that behaviors that facilitate assortative mating and reproductive success in individuals can be influenced by their social backgrounds. In species for which social learning plays an important role in the ontogeny of courtship behaviors and mating preferences, understanding the social-learning process and transmis- sion mechanisms will be necessary if we are to understand the evolutionary processes affecting those populations. Behaviors that are learned socially can diffuse quickly through populations. The rapid spread of behavioral traditions through social learning, by affecting the social environment generally and reproductive behavior specifically, can alter selection pressures acting within populations (Boyd \& Richerson, 1985; Laland, 1992; Lewontin, 1983). In short, to understand how behavioral and other traits may change over time in populations in which social learning is an important developmental factor, we need to take that social learning into account and understand how it operates.

Perhaps the greatest concern in trying to address the question of social learning and courtship behaviors in animals is that, to date, the question has been asked with respect to few species. Most studies on song learning in birds have involved only a handful of species, and links between song learning, song use, and actual courtship behavior and reproductive success are rarely made (Freeberg, 2000; West, King, \& Freeberg, 1994). Similarly, studies of mate-choice copying have been carried out in only a small number of species.

Because of the paucity of species studied, we cannot yet answer many basic questions. How prevalent is social learning of courtship behaviors and mating preferences in oscine songbirds? In birds? In mammals? Are there commonalities to the social organization of those species that exhibit social learning (see, e.g., Bekoff, Allen, \& Burghardt, 2002; Byrne \& Whiten, 1988; Coussi-Korbel \& Fragaszy, 1995) that could lead us to expect social transmission of courtship behaviors in divergent taxa that share key aspects of their social structure? Alternatively, is social transmission of courtship behavior limited to certain phylogenetic lineages? For example, to date, the learning of song has been demonstrated in only three groups of birds: oscine songbirds, hummingbirds, and parrots (Kroodsma \& Miller, 1996).

Coussi-Korbel and Fragaszy (1995) have proposed that "within stable social groups, long-term social relationships develop, and dynamic social processes influence all aspects of life . . . . It seems likely that the specific social context in which a group-living animal finds itself influences its opportunities for social learning, and perhaps also its propensity to learn certain things from certain individuals" (p. 1441). They argued that some key features of groups that may influence social learning are such factors as the stability of group membership over time and interindividual behavioral structures, such as dominancehierarchies. By comparing different species, we might predict social learning to be absent or present and, if present, to vary in predictable ways based on the social dynamics of groups in those species. For example, one might expect an increased propensity for observational learning in social, as opposed to solitary, corvid species of birds (see, e.g., Balda \& Kamil, 2002) and an increased ability to learn from the foraging behaviors of 
others in social, as opposed to solitary, rodent species (e.g., Galef, 1996; Timberlake, 1983). If different populations face different selection pressures affecting the social structure, we might also expect to see a geographic variation in the influences of social learning within a species. For example, studies of different populations of songbirds have shown differences in the rates and timing of song development that relate to the natural histories of the populations studied, including onset of breeding season and migratory/resident status of the population(Freeberg, West, King, Duncan, \& Sengelaub, 2002; Kroodsma \& Canady, 1985; Nelson, Marler, \& Palleroni, 1995).

In conjunction with the pursuit of questions concerning the relationships between social structure and possibility of social learning of courtship behaviors and mating preferences with a greater number and diversity of species, more work that will uncover the processes of social transmission is needed. For a young animal (or an animal dispersing or migrating into a new group with different behaviors), what are the salient features of the social environment to which it must attend? Do behaviors it might develop stem primarily from observational learning (e.g., by watching an experienced adult interact with others in the group), or are such behaviors also shaped extensively by the consequences of performing them in a social group? In male cowbirds, for example, a young male's songs early in development can be influenced heavily by visual displays and movement patterns of female cowbirds (Smith, King, \& West, 2000; West \& King, 1988). Much less is known about the influences other males may have on a young male's songs early in development, although adult males clearly influence song development in young males (Freeberg et al., 1995; West \& King, 1980). Detailed longitudinal assessments of young males interacting in their social groups and of young males observing interactions of others during the development of their songs will be needed. The data collected to date indicate that pinpointing the effects of older males on younger males' songs may be difficult (White et al., 2002b). The learning process by which female courtship behaviors and preferences are influenced by the social group remains largely unknown.

Flinn (1997) has argued that naive individuals need "to learn the right thing at the right time from the right role model" (p. 34). This view suggests an active assessment of the social environment by the naive individual. What strategies do young or naive animals use in learning courtship behaviors and mating preferences? Should an individual react only to others that initiate behaviors, or should it initiate behaviors with others? Should an individual imitate or emulate successful individuals in the group, follow the majority by learning the most common behavioral patterns, or use some other strategy? We have few answers to these questions for any species and so are unable to address fundamental questions about the social transmission of courtship behaviors.
To summarize, research with brown-headed cowbirds has illustrated the social transmission of behavior patterns that facilitate courtship behaviors, mating preferences, and assortative mating. Recent work has shed light on some important social mechanisms by which young birds, particularly young male birds, learn the vocal signals they will use and, perhaps more importantly, how to use those signals effectively. Because these socially transmitted behaviors and preferences play a fundamental role in determining the reproductive success of individuals, this work indicates that social learning may influence how sexual selection operates on populations and, therefore, how these behavior systems may evolve in populations over time. Increased efforts toward the understanding of mechanisms by which courtship behaviors and mating preferences are transmitted among individuals and across generations are needed. Finally, increased comparative work that tests links between the social dynamics of group organization and the type and extent of social learning that occur would shed light on the sorts of selection pressures that influence social learning in different species and in different populations within a species.

\section{REFERENCES}

BALDA, R. F., \& KAMIL, A. C. (2002). Spatial and social cognition in corvids: An evolutionary approach. In M. Bekoff, C. Allen, \& G. M. Burghardt (Eds.), The cognitive animal: Empirical and theoretical perspectives on animal cognition (pp. 129-134). Cambridge, MA: MIT Press.

Bekoff, M., Allen, C., \& Burghardt, G. M. (Eds.) (2002). The cognitive animal: Empirical and theoretical perspectives on animal cognition. Cambridge, MA: MIT Press.

BOYD, R., \& RiCHERSON, P. J. (1985). Culture and the evolutionary process. Chicago, IL: University of Chicago Press.

Brooks, R. (1996). Copying and the repeatability of mate choice. Behavioral Ecology \& Sociobiology, 39, 323-329.

BYRne, R. W., \& Whiten, A. (EDS.) (1988). Machiavellian intelligence. Oxford: Oxford University Press, Clarendon Press.

Catchpole, C. K., \& Slater, P. J. B. (1995). Bird song: Biological themes and variations. Cambridge: Cambridge University Press.

Clayton, N. S. (1990). Assortative mating in zebra finch subspecies, Taeniopygia guttata guttata and T. g. castanotis. PhilosophicalTransactions of the Royal Society of London: Series B, 330, 351-370.

Coussi-Korbel, S., \& Fragaszy, D. M. (1995). On the relation between social dynamics and social learning. Animal Behaviour, 50, 1441-1453.

Domjan, M., Blesbois, E., \& Williams, J. (1998). The adaptive significance of sexual conditioning: Pavlovian control of sperm release. Psychological Science, 9, 411-415.

Dugatkin, L. A. (1992). Sexual selection and imitation: Female copy the mate choice of others. American Naturalist, 139, 1384-1389.

Dugatkin, L. A., \& Godin, J.-G. (1992). Reversal of female mate choice by copying in the guppy (Poecilia reticulata). Proceedings of the Royal Society of London: Series B, 249, 179-184.

EAST ZE R, D. H., KING, A. P., \& WEST, M. J. (1985). Patterns of courtship between cowbird subspecies: Evidence for positive assortment. Animal Behaviour, 33, 30-39.

FISHE R, R. A. (1958). The genetical theory of natural selection (2nd ed.). New York: Dover.

FlinN, M. V. (1997). Culture and the evolution of social learning. Evolution \& Human Behavior, 18, 23-67.

FreE BERG, T. M. (1996). Assortative mating in captive cowbirds is predicted by social experience. Animal Behaviour, 52, 1129-1142. 
FREEBERG, T. M. (1998). The cultural transmission of courtship patterns in cowbirds, Molothrus ater. Animal Behaviour, 56, 1063-1073.

FrEEBERG, T. M. (1999). Spatial associations provide a context for social learning of courtship patterns in brown-headed cowbirds (Molothrus ater). Journal of Comparative Psychology, 113, 327-332.

FREE BERG, T. M. (2000). Culture and courtship in vertebrates: A review of social learning and transmission of courtship systems and mating patterns. Behavioural Processes, 51, 177-192.

Freeberg, T. M., Duncan, S. D., Kast, T. L., \& Enstrom, D. A. (1999). Cultural influences on female mate choice: An experimental test in cowbirds (Molothrus ater). Animal Behaviour, 57, 421-426.

Freeberg, T. M., King, A. P., \& West, M. J. (1995). Social malleability in cowbirds (Molothrus ater artemisiae): Species and mate recognition in the first 2 years of life. Journal of Comparative Psychology, 109, 357-367.

Freeberg, T. M., King, A. P., \& West, M. J. (2001). Cultural transmission of vocal traditions in cowbirds (Molothrus ater) influences courtship patterns and mate preferences. Journal of Comparative Psychology, 115, 201-211.

Freeberg, T. M., West, M. J., King, A. P., Duncan, S. D., \& Sengelaub, D. R. (2002). Cultures, genes, and neurons in the development of song and singing in brown-headed cowbirds (Molothrus ater). Journal of Comparative Physiology A, 188, 993-1002.

Friedmann, H. (1929). The cowbirds: A study in the biology of social parasitism. Springfield, IL: Thomas.

GALEF, B. G., JR. (1996). Social enhancement of food preferences in Norway rats: A brief review. In C. M. Heyes \& B. G. Galef, Jr. (Eds.), Social learning in animals: The roots of culture (pp. 49-64). San Diego: Academic Press.

Galef, B. G., JR., \& Allen, C. (1995). A new model system for studying behavioural traditions in animals. Animal Behaviour, 50, 705-717.

GALEF, B. G., JR., \& White, D. J. (1998). Mate-choice copying in Japanese quail, Coturnix coturnix japonica. Animal Behaviour, 55, 545-552.

Gros-Louis, J., White, D. J., King, A. P., \& West, M. J. (2003). Female brown-headed cowbirds' (Molothrus ater) social assortment changes in response to male song: A potential source of public information. Behavioral Ecology \& Sociobiology, 53, 163-173.

Gutierre Z,G., \& Domuan, M. (1997). Differences in the sexual conditioned behavior of male and female Japanese quail (Coturnix japonica). Journal of Comparative Psychology, 111, 135-142.

HARTL, D. L., \& ClARK, A. G. (1989). Principles of population genetics (2nd ed.). Sunderland, MA: Sinauer Associates.

Hess, E. H. (1973). Imprinting: Early experience and the developmental psychobiology of attachment. New York: Van Nostrand Reinhold.

Hollis, K. L., PharR, V. L., Dumas, M. J., Britton, G. B., \& Fie LD, J. (1997). Classical conditioning provides paternity advantage for territorial male blue gouramis (Trichogaster trichopterus). Journal of Comparative Psychology, 111, 219-225.

JENKINS, J. R., \& ROWLAND, W. J. (1996). Pavlovian conditioning of agonistic behavior in male threespine stickleback (Gasterosteus aculeatus). Journal of Comparative Psychology, 110, 396-401.

JENKINS, J. R., \& RowLAND, W. J. (1997). Learning influences courtship preferences of male threespine stickleback (Gasterosteus aculeatus). Ethology, 103, 954-965.

King, A. P., Freeberg, T. M., \& West, M. J. (1996). Social experience affects the process and outcome of vocal ontogeny in two populations of cowbirds (Molothrus ater). Journal of Comparative Psychology, 110, 276-285.

KING, A. P., \& WEST, M. J. (1987). Different outcomes of synergy between song production and song perception in the same subspecies (Molothrus ater ater). Developmental Psychobiology, 20, 177-187.

KÖKSAL, F., \& DOMJAN, M. (1998). Observational conditioning of sexual behavior in the domesticated quail. Animal Learning \& Behavior 26, 427-432.

Kroodsma, D. E., \& CANAdy, R. A. (1985). Differences in repertoire size, singing behavior, and associated neuroanatomy among marsh wren populations have a genetic basis. Auk, 102, 439-446.

Kroodsma, D. E., \& Mille R, E. H. (EDS.) (1996). Ecology and evolution of acoustic communication in birds. Ithaca, NY: Cornell University Press.
Kruijt, J. P., Bossemma, I., \& LAmmers, G. J. (1982). Effects of early experience and male activity on mate choice in mallard females (Anas platyrhynchos). Behaviour, 80, 32-43.

Kruit, J. P., \& MEeUWISSEN, G. B. (1991). Sexual preferences of male zebra finches: Effects of early and adult experience. Animal Behaviour, 42, 91-102.

LALAND, K. N. (1992). A theoretical investigation of the role of social transmission in evolution. Ethology \& Sociobiology, 13, 87-113.

Lewontin, R. C. (1983). Gene, organism, and environment. In D. S. Bendall (Ed.), Evolution from molecules to men (pp. 273-285). Cambridge: Cambridge University Press.

LORENZ, K. (1970). A consideration of methods of identification of species-specif ic instinctive behavior patterns in birds. In Studies in animal and human behaviour (Vol. 1). Cambridge, MA: Harvard University Press. (Originally published as "Betrachtungen über das Erkennen der arteigenen Triebhandlungen der Vögel" in Journal für Ornithologie, 1932, 80, 50-98)

MAYR, E. (1974). Behavioral programs and evolutionary strategies. American Scientist, 62, 650-659.

Nelson, D. A., Marler, P., \& Palleroni, A. (1995). A comparative approach to vocal learning: Intraspecific variation in the learning process. Animal Behaviour, 50, 83-97.

O'Loghlen, A. L., \& Rothstein, S. I. (1993). An extreme example of delayed vocal development: Song learning in a population of wild brown-headed cowbirds. Animal Behaviour, 46, 293-304.

O'Loghlen, A. L., \& Rothstein, S. I. (2002). Ecological effects on song learning: Delayed vocal development is widespread in wild populations of brown-headed cowbirds. Animal Behaviour, 63, 475-486.

ORTEGA, C. P. (1998). Cowbirds and other brood parasites. Tucson: University of Arizona Press.

Rothstein, S. I., Yokel, D. A., \& Fleischer, R. C. (1986). Social dominance, mating and spacing systems, female fecundity, and vocal dialects in captive and free-ranging brown-headed cowbirds. In R. F. Johnston (Ed.), Current ornithology(Vol. 3, pp. 127-185). New York: Plenum.

Smith, V. A., King, A. P., \& West, M. J. (2000). A role of her own: Female cowbirds (Molothrus ater) influence the development and outcome of song learning. Animal Behaviour, 60, 599-609.

Smith, V. A., KInG, A. P., \& West, M. J. (2002). The context of social learning: Association patterns in a captive flock of brown-headed cowbirds. Animal Behaviour, 63, 23-35.

TEN CATE, C. (1984). The influence of social relations on the development of species recognition in zebra finch males. Behaviour, 91, 263285 .

ten Cate, C., Hilbers, J., \& Hall, M. (1992). Sexual imprinting in the collared dove (Streptopelia decaocto). Behaviour, 122, 41-55.

TIMBERLAKE, W. (1983). The functional organization of appetitive behavior: Behavior systems and learning. In M. D. Zeiler \& P. Harzem (Eds.), Advances in the analysis of behavior: Vol. 3. Biological factors in learning (pp. 177-221). New York: Wiley.

Vos, D. R. (1994). Sex recognition in zebra finch males results from early experience. Behaviour, 128, 1-14.

West, M. J., \& KING, A. P. (1980). Enriching cowbird song by social deprivation. Journal of Comparative \& Physiological Psychology, 94, 263-270.

WeSt, M. J., \& KING, A. P. (1988). Female visual displays affect the development of male song in the cowbird. Nature, 334, 244-246.

West, M. J., King, A. P., \& EAstzer, D. H. (1981). Validating the female bioassay of cowbird song: Relating differences in song potency to mating success. Animal Behaviour, 29, 490-501.

West, M. J., King, A. P., \& FreeberG, T. M. (1994). The nature and nurture of neophenotypes. In L. A. Real (Ed.), Behavioral mechanisms in evolutionary ecology (pp. 238-257). Chicago: University of Chicago Press.

West, M. J., King, A. P., \& Freeberg, T. M. (1998). Dual signaling during mating in brown-headed cowbirds (Molothrus ater; Family Embirizidae/Icterinae). Ethology, 104, 250-267.

West, M. J., King, A. P., \& HARrocks, T. J. (1983). Cultural transmission of cowbird song (Molothrus ater): Measuring its development and outcome. Journal of Comparative Psychology, 97, 327-337. 
West, M. J., White, D. J., \& King, A. P. (2002). Female brown-headed cowbirds', Molothrus ater, organization and behaviour reflects male social dynamics. Animal Behaviour, 64, 377-385.

White, D. J. (2004). Influences of social learning on mate-choice decisions. Learning \& Behavior, 32, 105-113.

White, D. J., \& GALEF, B. G., JR. (1999). Mate choice copying and conspecific cueing in Japanese quail, Coturnix coturnix japonica. Animal Behaviour, 57, 465-473.

White, D. J., \& GALEF, B. G., JR. (2000). "Culture" in quail: social influences on mate choices of female Coturnix japonica. Animal Behaviour, 59, 975-979.
White, D. J., King, A. P., Cole, A., \& West, M. J. (2002). Opening the social gateway: Early vocal and social sensitivities in brown-headed cowbirds (Molothrus ater). Ethology, 108, 23-37.

White, D. J., KInG, A. P., \& West, M. J. (2002a). Facultative development of courtship and communication in juvenile male cowbirds (Molothrus ater). Behavioral Ecology, 13, 487-496.

White, D. J., King, A. P., \& West, M. J. (2002b). Plasticity in adult development: Experience with young males enhances mating competence in adult male cowbirds, Molothrus ater. Behaviour, 139, 713-728.

WOODWARD, P. W. (1983). Behavioral ecology of fledgling brownheaded cowbirds and their hosts. Condor, 85, 151-163. 